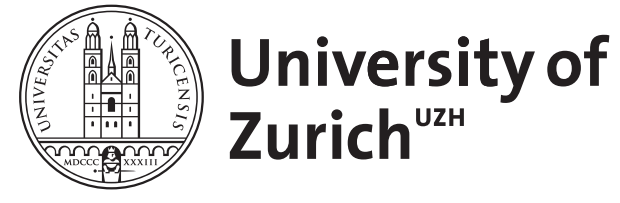
Archive

University of Zurich

University Library

Strickhofstrasse 39

CH-8057 Zurich

www.zora.uzh.ch

Year: 2013

Is there still a role for thiopurines in Crohn's disease?

Rogler, Gerhard ; Sandborn, William J

DOI: https://doi.org/10.1053/j.gastro.2013.08.022

Posted at the Zurich Open Repository and Archive, University of Zurich

ZORA URL: https://doi.org/10.5167/uzh-92832

Journal Article

Accepted Version

Originally published at:

Rogler, Gerhard; Sandborn, William J (2013). Is there still a role for thiopurines in Crohn's disease? Gastroenterology, 145(4):714-716.

DOI: https://doi.org/10.1053/j.gastro.2013.08.022 


\section{Is there still a role for thiopurines in Crohn's}

\section{disease?}

Gerhard Rogler ${ }^{1}$ and William J. Sandborn ${ }^{2}$

${ }^{1}$ Department of Gastroenterology \& Hepatology, University Hospital of Zürich, Zürich,

Switzerland

${ }^{2}$ Chief, Division of Gastroenterology, UC San Diego Campus, San Diego, USA 
The history of thiopurines (azathioprine, 6-mercaptopurine) and Crohn's disease has been many years in the making. In 1979 Summers reported on behalf of the National Cooperative Crohn's Disease Study (NCCDS) that azathioprine (AZA) $2.5 \mathrm{mg} / \mathrm{kg} /$ day was not effective for induction of remission over 16 weeks, or for maintenance of remission therapy over 1 year-. ${ }^{1}$ In 1980 Present reported that 6-mercaptopurine (6MP) $1.5 \mathrm{mg} / \mathrm{kg} /$ day was effective as induction and maintenance therapy over 1 year. ${ }^{2}$ In this trial, the mean time to response was reported to be 3.1 months, requiring up to 6 months to reach maximal clinical efficacy in some patients. Due to these contradictory data, for the next decade, there was controversy regarding the efficacy of thiopurine medications for Crohn's disease. In 1995, Pearson and Sutherland performed a metaanalysis which concluded that thiopurines were effective for induction and maintenance therapy, and that clinical results were optimized if patients were treated for at least 16 weeks. ${ }^{3}$ Thereafter, thiopurine use in Crohn's disease gained widespread acceptance, and has been incorporated into multiple treatment guidelines. ${ }^{4,5}$

However, the treatment effect of thiopurines for Crohn's disease has continued to be inconsistent. The most recent Cochrane Library meta-analyses reported that thiopurines are not effective for induction of remission ${ }^{6}$, but are effective for maintenance of remission and for steroid sparing ${ }^{7}$, and another meta-analysis reported efficacy of thiopurines for prevention of post-operative recurrence. ${ }^{8}$

Given the inconsistency of treatment effects, controversy has persisted regarding the appropriate role of thiopurines in the treatment of Crohn's disease. Clinical trials published over the last 10 plus years have demonstrated that the maximum clinical effect of thiopurines plateaus after 8 weeks of therapy ${ }^{9,10}$ and that the absolute rates of remission are in the range of $25-30 \%{ }^{1,9,10}$. When risks and benefits of therapy are discussed, it must to be kept in mind that thiopurines are 
associated with important toxicities including non-Hodgkins lymphoma linked to the Epstein Barr virus ${ }^{11-13}$, hepatosplenic T cell lymphoma ${ }^{14}$, and non-melanoma skin cancer. ${ }^{15}$ Comparative effectiveness trials demonstrated that thiopurine monotherapy was less effective than combination therapy with thiopurines and TNF antagonists for induction and maintenance of steroid free remission over 6-12 months. ${ }^{10,16}$

In 2000, Markowitz and colleagues reported that 6MP significantly lessened the need for prednisone and improved maintenance of remission in a study of 55 pediatric patients with new onset Crohn's disease who received a tapering course of prednisone. ${ }^{17}$ However, the precise details of the reported results are that by 3 months, all 6MP patients and all but 1 placebo patient had achieved at least 1 inactive Harvey Bradshaw score, and that by 12 months, both groups had cumulative remission rates of $89 \%$. Among those in remission, 1 patient (4\%) in the $6 \mathrm{MP}$ group had a relapse within 180 days of achieving remission, compared with 7 patients (28\%) in the placebo group ( $\mathrm{p}$ value not given). Based on this study, it has subsequently been proposed that "top down" therapy with thiopurines and a tapering course of steroids could serve as an alternative to the more recently described treatment strategy of top down therapy with TNF antagonists in patients with newly diagnosed or early Crohn's disease. ${ }^{18}$ However, given that the Markowitz trial only had 55 patients, was conducted in pediatric patients, and did not demonstrate definitive differences in remission rates, more data were needed to better assess the efficacy of combination therapy with a thiopurine and steroids in adult patients with newly diagnosed Crohn's disease. In this issue of Gastroenterology contains the results of two such studies, reported by Cosnes and Panes. ${ }^{19,20}$ 
Cosnes (for the GETAID group) reported on an open-label randomized trial in 147 adult patients with newly diagnosed $\mathrm{CD}$ (less than 6 months) and risk factors for disabling disease (patients were considered at high risk of disabling disease based on the presence of at least two of the following criteria: age $<40$ years, active perianal lesions, and corticosteroid use within 3 months of diagnosis) recruited at 24 French centers. ${ }^{19}$ The patients were randomized to receive early immunosuppression with AZA $2.5 \mathrm{mg} / \mathrm{kg} / \mathrm{day}$ or conventional management. Prednisone or budesonide was administered for disease flares, and if necessary patients could be switched to other immunosuppressive medications and could receive anti-TNF therapy. Among the conventional management patients, $61 \%$ eventually received AZA. Among early AZA patients, $25 \%$ had to be switched to another immunosuppressant due to intolerance to AZA. The primary end-point, which was the proportion of trimesters spent in steroid-free and anti-TNF-free remission during an observation period of 3 years, occurred in 67\% of the early AZA group and $56 \%$ of the conventional management group $(\mathrm{p}=0.69)$. For the secondary endpoints, there were no significant differences between the two groups in the proportions of trimesters with disease flare, hospitalization, intestinal surgery or use of TNF antagonists, with the exception of the proportion of $\mathrm{CD}$ patients not requiring perianal surgery which was higher in the early-AZA group $(\mathrm{p}=0.036)$. Total exposure to prednisone and budesonide were also not significantly different between the groups. Cosnes concluded that early AZA was not more effective than conventional management in adult patients with newly diagnosed $\mathrm{CD}$ for increasing time on clinical remission over 3 years after diagnosis.

Panes (for the AZTEC study group) reported on a double-blind, placebo-controlled trial in 131 adult patients with newly diagnosed CD (less than 8 weeks) recruited at 31 Spanish centers. ${ }^{20}$ 
Patients were randomized to receive AZA $2.5 \mathrm{mg} / \mathrm{kg} /$ day or placebo. Approximately $70 \%$ of patients were received steroids at baseline, and subsequently prednisone or budesonide was administered for disease flares (defined as a CDAI score greater than 175 points). The primary end-point, steroid-free remission at 76 weeks, occurred in $44 \%$ of the early AZA group and $37 \%$ of the placebo group ( $\mathrm{p}=0.48$ ). For the secondary endpoints, there were no significant differences between the groups in the proportion of patients with steroid free remission at week 28 or week 50, and there were no significant differences in relapse free survival rates, or in CDAI scores or CRP concentrations over time. The use of steroids was not significantly different between the groups. In a post-hoc subgroup analysis, when relapse was defined as an increase in the CDAI score to greater than 220 points, then the relapse rate was significantly lower in the early AZA group ( $12 \%$ versus $30 \%$ in the placebo group, $\mathrm{p}=0.01$ ). Panes concluded that in early AZA was not more effective than placebo in adult patients with newly diagnosed $\mathrm{CD}$ for achieving sustained steroid-free remission over 76 weeks.

Where does this additional information leave the practicing gastroenterologist and the patient? First, the primary endpoints for these two studies demonstrate that early "top down" therapy with thiopurine therapy is not more effective that placebo or conventional therapy in adults with newly diagnosed CD (although some subgroups of patients may have benefited). ${ }^{19,20}$ These results cast some doubt as to whether the results of a small pediatric study have any relevance for adult patients with newly diagnosed $\mathrm{CD} .{ }^{17}$ Second, we should acknowledge that the most recent Cochrane Library meta-analysis demonstrated that thiopurines are not effective for induction of remission in $\mathrm{CD} .{ }^{6}$ Third, the most recent Cochrane Library meta-analysis demonstrated that thiopurines are modestly effective for maintenance of steroid induced remission ${ }^{7}$, and another 
meta-analysis demonstrated a modest effect for prevention of post-operative recurrence. ${ }^{8}$ With regard to these two indications, it must be kept in mind that when thiopurines are combined with corticosteroids, the relative risks of serious infection and mortality from infection are markedly increased. $^{21,22}$

Thus, the two remaining indications for primary therapy with thiopurines are maintenance of steroid induced remission/steroid sparing in patients with CD which is not newly diagnosed ${ }^{7}$, and prevention of post-operative recurrence ${ }^{8}$, each of which has a modest effect size that must be weighed against the risks of the medications. Two comparative effectiveness trials have demonstrated unequivocal superiority of combination therapy with thiopurines and TNF antagonist therapy with infliximab as compared with thiopurines alone, with no incremental increase in toxicity. ${ }^{10,16}$ Therefore, the strongest indication for thiopurines may be as part of a combination therapy regimen. The recent post-hoc study reporting that combination therapy is more effective with infliximab than with adalimumab or certolizumab ${ }^{23}$ is not reassuring, given that patients were not randomized to TNF antagonist monotherapy or combination therapy, and the results are not logical since drug withdrawal data with certolizumab show rates of immunogenicity with monotherapy that approach those observed with infliximab. ${ }^{24}$ There are not yet comparative effectiveness data for thiopurines and TNF antagonists for the indication of prevention of post-operative recurrence, but early data suggest a very large effect size for TNF antagonists. $^{25,26}$ If TNF antagonists had a similar low cost as generic thiopurines, there would likely be little debate regarding an evolution towards treatment of CD with TNF antagonists, either as monotherapy or ideally as combination therapy. Unfortunately, this is not the world that we live in. Currently, the annual costs of TNF antagonists is 10-20 times that of thiopurines, and 
large differences in costs are likely to persist even after the advent of biosimilars. ${ }^{27}$ In rheumatoid arthritis (RA), the use of TNF antagonists in very early RA provides the highest level of efficacy, but the use of methotrexate is the most cost effective strategy, thus providing the best value for society. ${ }^{28}$ Although the efficacy of methotrexate in RA is more robust than the efficacy of thiopurines in $\mathrm{CD}$, the analogy nevertheless persists. Because of the big difference in cost between thiopurines and TNF antagonists, the use of thiopurines in CD is likely to persist, despite the shrinking number of indications, the modest effect size, and the sub-optimal safety profile. 


\section{References}

1. Summers RW, Switz DM, Sessions JT, Jr., et al. National Cooperative Crohn's Disease Study: results of drug treatment. Gastroenterology 1979;77:847-69.

2. Present $\mathrm{DH}$, Korelitz BI, Wisch N, et al. Treatment of Crohn's disease with 6-mercaptopurine. A long-term, randomized, double-blind study. N Engl J Med 1980;302:981-7.

3. Pearson DC, May GR, Fick GH, et al. Azathioprine and 6-mercaptopurine in Crohn disease. A meta-analysis. Annals of Internal Medicine 1995;123:132-42.

4. Lichtenstein GR, Hanauer SB, Sandborn WJ. Management of Crohn's disease in adults. . American Journal of Gastroenterology 2009;104:465-483.

5. Dignass A, Van Assche G, Lindsay JO, et al. The second European evidence-based Consensus on the diagnosis and management of Crohn's disease: Current management. J Crohns Colitis 2010;4:28-62.

6. Chande N, Tsoulis DJ, MacDonald JK. Azathioprine or 6-mercaptopurine for induction of remission in Crohn's disease. Cochrane Database Syst Rev 2013;4:CD000545.

7. Prefontaine E, Macdonald JK, Sutherland LR. Azathioprine or 6-mercaptopurine for induction of remission in Crohn's disease. Cochrane Database Syst Rev 2010:CD000545.

8. Peyrin-Biroulet L, Deltenre P, Ardizzone S, et al. Azathioprine and 6-mercaptopurine for the prevention of postoperative recurrence in Crohn's disease: a meta-analysis. Am J Gastroenterol 2009;104:2089-96.

9. Sandborn WJ, Tremaine WJ, Wolf DC, et al. Lack of effect of intravenous administration on time to respond to azathioprine for steroid-treated Crohn's disease. North American Azathioprine Study Group. Gastroenterology 1999;117:527-35.

10. Colombel JF, Sandborn WJ, Reinisch W, et al. Infliximab, azathioprine, or combination therapy for Crohn's disease. New England Journal of Medicine 2010;362:1383-95.

11. Dayharsh GA, Loftus EV, Jr., Sandborn WJ, et al. Epstein-Barr virus-positive lymphoma in patients with inflammatory bowel disease treated with azathioprine or 6-mercaptopurine.

Gastroenterology 2002;122:72-7.

12. Kandiel A, Fraser AG, Korelitz BI, et al. Increased risk of lymphoma among inflammatory bowel disease patients treated with azathioprine and 6-mercaptopurine.[see comment]. Gut 2005;54:1121-5.

13. Beaugerie L, Brousse N, Bouvier AM, et al. Lymphoproliferative disorders in patients receiving thiopurines for inflammatory bowel disease: a prospective observational cohort study. Lancet 2009;374:1617-25.

14. Kotlyar DS, Osterman MT, Diamond RH, et al. A systematic review of factors that contribute to hepatosplenic T-cell lymphoma in patients with inflammatory bowel disease. Clin Gastroenterol Hepatol 2011;9:36-41 e1.

15. Peyrin-Biroulet L, Khosrotehrani K, Carrat F, et al. Increased risk for nonmelanoma skin cancers in patients who receive thiopurines for inflammatory bowel disease. Gastroenterology 2011;141:1621-28 e1-5.

16. Lemann M, Mary JY, Duclos B, et al. Infliximab plus azathioprine for steroid-dependent Crohn's disease patients: a randomized placebo-controlled trial.[see comment]. Gastroenterology 2006;130:1054-61.

17. Markowitz J, Grancher K, Kohn N, et al. A multicenter trial of 6-mercaptopurine and prednisone in children with newly diagnosed Crohn's disease. Gastroenterology 2000;119:895-902.

18. D'Haens G, Baert F, van Assche G, et al. Early combined immunosuppression or conventional management in patients with newly diagnosed Crohn's disease: an open randomised trial. Lancet 2008;371:660-7. 
19. Cosnes J, Bourrier A, Laharie D, et al. Early Administration of Azathioprine vs Conventional Management of Crohn's Disease: a Randomized Controlled Trial. Gastroenterology 2013.

20. Panés J, López-SanRomán A, Bermejo F, et al. Early azathioprine therapy is no more effective than placebo for newly diagnosed Crohn's disease. Gastroenterology 2013;(In Press).

21. Lichtenstein GR, Feagan BG, Cohen RD, et al. Serious infections and mortality in association with therapies for Crohn's disease: TREAT registry. Clinical Gastroenterology \& Hepatology 2006;4:621-30.

22. Lewis JD, Gelfand JM, Troxel AB, et al. Immunosuppressant medications and mortality in inflammatory bowel disease. American Journal of Gastroenterology 2008;103:1428-1435.

23. Jones J, Kaplan GG, Peyrin-Biroulet L, et al. Impact of concomitant immunomodulator treatment on efficacy and safety of anti-TNF therapy in Crohn's disease: a meta-analysis of placebo controlled trials with individual patient-level data. Gastroenterology Clinics of North America 2013;144 (Suppl 1):S-179.

24. Schreiber s, Khaliq-Kareemi M, Lawrance I, et al. Certolizumab pegol maintenance therapy for Crohn's disease. New England Journal of Medicine 2007;357:239-250.

25. Regueiro M, Schraut W, Baidoo L, et al. Infliximab prevents Crohn's disease recurrence after ileal resection. Gastroenterology 2009;136:441-50 e1; quiz 716.

26. Savarino E, Bodini G, Dulbecco P, et al. Adalimumab is more effective than azathioprine and mesalamine at preventing postoperative recurrence of Crohn's disease - a randomized trial. Gaastroenterology 2013;144 (Suppl 1):S-21.

27. Gecse KB, Khanna R, van den Brink GR, et al. Biosimilars in IBD: hope or expectation? Gut 2013;62:803-7.

28. Finckh A, Bansback N, Marra CA, et al. Treatment of very early rheumatoid arthritis with symptomatic therapy, disease-modifying antirheumatic drugs, or biologic agents: a costeffectiveness analysis. Ann Intern Med 2009;151:612-21. 